\author{
Military Technical College \\ Kobry El-Kobbah, \\ Cairo, Egypt.
}

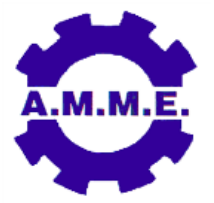

\section{HIGH ALTITUDE FLYING WING UAV FOR AUTOMATIC PAYLOAD RECOVERY AND HIGH ALTITUDE TESTS OF NOVEL PROPULSION UNITS}

\author{
F. Mingireanu ${ }^{1}$
}

$17^{\text {th }}$ International Conference
on Applied Mechanics and
Mechanical Engineering.

\begin{abstract}
A high altitude flying wing UAV is presented together with test flights performed in Finland in July, 2014 and June, 2015 in support of European Space Agency (ESA) Earth surveillance missions. The UAV uses an innovative inertial autopilot, which is able to automatically steer the flying wing UAV from $30 \mathrm{~km}$ altitude to targets placed at several hundred kilometers with meters accuracy. The detailed system is presented together with the communication capabilities from high altitude and long ranges. It is also presented the capability to fly automatically without high altitude GPS capability.
\end{abstract}

A complete 6 DOF flight dynamics model is presented together with its implementation on the autopilot. The 6 DOF model is also used for flight performance predictions which are in good agreement with the experimental results obtained from the abovementioned test flights. The 6 DOF uses a non-spherical, rotating Earth system which gives global coverage for the simulations performed within the model as well as for the autopilot based on this model. The 6 DOF model is used both for flight dynamics assessment as well as a basis for the autopilot software running onboard the UAV and used for automatically flying the UAV. Very good agreement between the inertial autopilot and the radio tracking is shown through a trajectory comparison.

Various applications are envisioned for the high altitude flying wing UAV beyond the support for automatic payload recovery. These applications take advantage of the high efficiency design and high precision (5-10 meters) achievable at long ranges (600 km range).

As a potential application, we also propose an innovative propulsion unit to be tested onboard the high altitude UAVs. This innovative propulsion unit uses ozone dissociation present at high altitude in order to extend the coverage range of the UAV. In this seminar, we present a simplified model of ozone dissociation together with the initial trajectories requirements for such an UAV to take advantage of ozone dissociation at $30.000 \mathrm{~m}$ altitude.

1 Romanian Space Agency, Str. Mendeleev; Nr. 21-25, Bucharest, sector 1, 10362 , Romania, E-mail: florin.mingireanu@rosa.ro. 